[3] Li PH, Ko KL, Ho CT, Lau LL, Tsang RK, Cheung TT, et al. Immunoglobulin G4-related disease in Hong Kong: clinical features, treatment practices, and its association with multisystem disease. Hong Kong Med J. 2017, 23: 446-53.

[4] Culver EL, Sadler R, Bateman AC, Makuch M, Cargill T, Ferry B, et al. Increases in IgE, Eosinophils, and Mast Cells Can be Used in Diagnosis and to Predict Relapse of IgG4-Related Disease. Clin Gastroenterol Hepatol. 2017, 15: 1444-52.

[5] Inoue D, Yoshida K, Yoneda N, Ozaki K, Matsubara T, Nagai K, et al. IgG4-related disease: dataset of 235 consecutive patients. Medicine (Baltimore). 2015, 94: e680.

[6] Brito-Zeron P, Kostov B, Bosch X, Acar-Denizli N, Ramos-Casals M, Stone $\mathrm{JH}$. Therapeutic approach to IgG4-related disease: A systematic review. Medicine (Baltimore). 2016, 95: e4002.

[7] Peng Y, Li JQ, Zhang PP, Zhang X, Peng LY, Chen H, et al. Clinical outcomes and predictive relapse factors of IgG4-related disease following treatment: a long-term cohort study. J Intern Med. 2019.

Acknowledgments: This work was supported by the National Natural Science Foundation of China (NSFC 81601398; NSFC 81771730); the Animal Research Project of Shanghai Science and Technology Commission (grant number 17140902000); and Shanghai Pujiang Rheumatologists Training Program (SPROG201801)

Disclosure of Interests: None declared

DOI: 10.1136/annrheumdis-2020-eular.4005

\section{AB1245 DAILY MANAGEMENT OF PATIENTS WITH AXIAL SPONDYLOARTHRITIS: SELF-MONITORING OF DISEASE ACTIVITY WITH A SMARTPHONE APP IS FEASIBLE - A PROOF OF CONCEPT STUDY}

U. Kiltz ${ }^{1}$, R. Kempin ${ }^{1}$, A. Schlegel ${ }^{1}$, X. Baraliakos ${ }^{1}$, S. Tsiami ${ }^{1}$, B. Buehring ${ }^{1}$, D. Kiefer ${ }^{1}$, J. Braun ${ }^{1}$ on behalf of n/a. ${ }^{1}$ Rheumazentrum Ruhrgebiet Herne and Ruhr University Bochum, Herne, Germany

Background: Assessment and monitoring of disease activity and functioning is of major importance for the course of axial spondyloarthritis (axSpA). This is equally important for patient monitoring in daily routine as also for tight control strategies. Even though there is evidence that a closer monitoring of patients is better than routine care, more intensive treatment schedules are often not realized in daily practice for several reasons including shortage of time and personal resources. Using application software devices (apps) in clinical routine for the recording of disease-specific patient reported outcomes (PRO) may facilitate monitoring and improve clinical decision processes but there is a lack of data on the use of apps.

Objectives: To investigate the use of such App technology in respect to usability, feasibility and equivalence of data in daily care of patients with axSpA. In more detail, it will be first determined how many patients are capable and ready to use the technology in a routine setting. Furthermore, the usage and behavior of patients using the app will be studied, the usability of the app and the equivalence of the collected parameters as well as the adherence to the documentation of disease activity over time.

Methods: Patients diagnosed with axSpA were consecutively included in this ongoing monocentric prospective cohort study. In addition to patient and disease characteristics, information on previous experience with digital health apps was collected. Patients were asked to submit BASDAI and BASFI scores regularly every 2 weeks. The free to use AxSpA Live App is available for Android and iOS as a Class I certified medical device.

Results: Out of 103 axSpA patients asked, 69 patients with axSpA (mean age $41.5 \pm 11.3,58 \%$ male, $76.8 \%$ use of bDMARDs, BASDAI $4.3 \pm 2.0$, BASFI $3.8 \pm 2.5$ ) out of 103 patients $(67 \%)$ agreed to use participate, while 5 did not have a smartphone, 1 was unable to download the app for technical reasons, 28 reported other personal reasons). Of the 69,62 patients $(89.9 \%)$ reported using electronic media frequently and had used digital health apps (mean apps used $1.0 \pm 1.3$ ) in everyday life before. There were no systematic differences between pain levels documented on paper or by app at baseline (ICC $0.9(95 \% \mathrm{Cl} 0.82-0.93)$. Out of 55 patients who completed week 2 , only 33 patients $(60 \%)$ used the App regularly to transmit their BASDAI/BASFI responses within the first two weeks $(60 \%)$. Patients who started a new drug treatment because of high disease activity, reported BASDAI values more often than patients without a treatment change within a follow-up period of $5.5 \pm 2.4$ weeks (Table).

Conclusion: The majority of patients with axSpA were able to use the AxSpA Live App. Most patients report scores regularly. The current disease activity seems to influence the adherence to reporting.

\begin{tabular}{lcc}
\hline & $\begin{array}{c}\text { Patients without change in } \\
\text { their medication (n=53) }\end{array}$ & $\begin{array}{c}\text { Patients with } \\
\text { change in their } \\
\text { medication } \\
(\mathbf{n}=16)\end{array}$ \\
\hline Age, years & $42.0(11.9)$ & $39.8(9.3)$ \\
Sex, male (\%) & 62.3 & 43.8 \\
BASDAl, baseline & $4.1(2.1)$ & $4.9(1.7)$ \\
BASFI, baseline & $3.8(2.6)$ & $3.8(2.3)$ \\
Time of follow-up, in weeks & $5.4(2.4)$ & $5.6(2.5)$ \\
Number of transmitted BASDAI values & $22(41 \%)$ & $11(69 \%)$ \\
$\quad$ at week 2 & $1.0(3.6)$ & $1.5(1.4)$ \\
$\quad \begin{array}{l}\text { Median number of transmitted BASDAI } \\
\text { values during follow up }\end{array}$ & & \\
\hline
\end{tabular}

This work was supported by an unrestricted Grant by Novartis Pharma GmbH, Germany

\section{Acknowledgments: $\mathrm{n} / \mathrm{a}$}

Disclosure of Interests: Uta Kiltz Grant/research support from: AbbVie, Amgen, Biogen, Novartis, Pfizer, Consultant of: AbbVie, Biocad, Eli Lilly and Company, Grünenthal, Janssen, Novartis, Pfizer, UCB, Speakers bureau: AbbVie, MSD, Novartis, Pfizer, Roche, UCB, Robin Kempin: None declared, Anna Schlegel: None declared, Xenofon Baraliakos Grant/research support from: Grant/research support from: AbbVie, BMS, Celgene, Chugai, Merck, Novartis, Pfizer, UCB and Werfen, Consultant of: AbbVie, BMS, Celgene, Chugai, Merck, Novartis, Pfizer, UCB and Werfen, Speakers bureau: AbbVie, BMS, Celgene, Chugai, Merck Novartis, Pfizer, UCB and Werfen, Styliani Tsiami: None declared, Bjoern Buehring Grant/research support from: GE/Lunar, Kinemed, Consultant of: Gilead, Abbvie Lilly, GE/Lunar, Janssen, Amgen, Speakers bureau: UCB, David Kiefer Grant/ research support from: Novartis, Juergen Braun Grant/research support from: Abbvie (Abbott), Amgen, BMS, Boehringer, Celgene, Celltrion, Centocor, Chugai, Eli Lilly and Company, Medac, MSD (Schering Plough), Mundipharma, Novartis Pfizer (Wyeth), Roche, Sanofi- Aventis, and UCB Pharma, Consultant of: Abbvie (Abbott), Amgen, BMS, Boehringer, Celgene, Celltrion, Centocor, Chugai, EBEWE Pharma, Eli Lilly and Company, Medac, MSD (Schering-Plough), Mundipharma Novartis, Pfizer (Wyeth), Roche, Sanofi-Aventis, and UCB Pharma, Speakers bureau: Abbvie (Abbott), Amgen, BMS, Boehringer, Celgene, Celltrion, Centocor Chugai, EBEWE Pharma, Eli Lilly and Company, Medac, MSD (Schering-Plough), Mundipharma, Novartis, Pfizer (Wyeth), Roche, Sanofi-Aventis, and UCB Pharma DOI: 10.1136/annrheumdis-2020-eular.3529

\section{AB1246 IDENTIFICATION OF GIANT CELL ARTERITIS IN REAL- WORLD DATA USING AN ADMINISTRATIVE CLAIMS- BASED ALGORITHM}

H. Lee ${ }^{1}$, S. Chen ${ }^{1,2}$, S. Tedeschi², P. Monach ${ }^{2}$, J. Liu' ${ }^{1}$ A. PethoeSchramm ${ }^{3}$, V. Yau ${ }^{4}$, S. Kim ${ }^{1,2}{ }^{1}$ Brigham and Women's Hospital, Division of Pharmacoepidemiology \& Pharmacoeconomics, Boston, United States of America; ${ }^{2}$ Brigham and Women's Hospital, Division of Rheumatology, Immunity and Inflammation, Boston, United States of America; ${ }^{3}$ F. Hoffmann-La Roche, Basel, Switzerland; ${ }^{4}$ Genentech, San Francisco, United States of America

Background: Giant cell arteritis (GCA), the most common systemic vasculitis in adults, is often associated with significant morbidity and mortality. A claimsbased algorithm that accurately identifies GCA patients in large real-world data can offer new opportunities for future epidemiological studies.

Objectives: We aimed to develop and validate a claims-based algorithm for GCA

Methods: We developed and tested 5 claims-based GCA algorithms using U.S Medicare claims (Parts $A / B / D$ ) linked to electronic medical record data from a large academic medical center, 2006-2014: Algorithm 1) $\geq 1$ International Classification of Diseases, Ninth Revision (ICD-9) code for GCA (446.5x) by any physician, high dose steroid dispensing (i.e., prednisone equivalent $\geq 40 \mathrm{mg} /$ day for $\geq 14$ days), and $\geq 1$ Current Procedural Terminology (CPT) code for ESR/CRP; 2 ) $\geq 1$ ICD-9 for GCA by a rheumatologist, high dose steroid dispensing, and ESR/CRP; 3 ) $\geq 2$ ICD-9 for GCA by a rheumatologist separated by 7-30 days and high dose steroid dispensing; 4) $\geq 1$ ICD-9 for GCA by a rheumatologist, high dose steroid dispensing, ESR/CRP and CPT code for temporal artery biopsy; and 5) $\geq 1$ ICD-9 for GCA or its subtypes $(447.6,437.4,417.8)$ by a rheumatologist, high dose steroid dispensing, ESR/CRP, and CPT code for chest imaging. For all algorithms, the index date was defined as the date of first steroid dispensing. Two physicians reviewed medical records for the gold standard definition of GCA: documentation of GCA by the treating physician or a temporal biopsy result consistent with GCA. Probable GCA cases based on treating physician's records were included as well. Positive predictive value (PPV) and $95 \%$ confidence intervals $(\mathrm{Cl})$ of the algorithms were calculated.

Results: We identified 1,930 patients with Medicare claims data linked to electronic medical records. Among these, 799 unique records with physician notes 